\title{
A Comparative Study on Effectiveness of Jigsaw Puzzle Method among General Nursing Diploma Students' Academic Level of Performance at Oman Nursing Institute, Muscat
}

\author{
Dr. Lakshmi Renganathan \\ Faculty, Oman College of Health Sciences, Muscat, Oman
}

\begin{abstract}
Background: There are many studies conducted on Cooperative Teaching and Learning methods shows that it improves level of academic performance yet no comparative study has been done among Jigsaw puzzle method.

Methods: Jigsaw Puzzle method is a Cooperative Teaching and Learning method was instituted for II year (162) and III year (127) General Nursing Diploma students. Quasi Experimental one group post-test design was adopted. After imparting jigsaw puzzle method, the quiz was conducted for both the groups at one week interval. Effectiveness of jigsaw was assessed and compared.

Results: The result indicates that the jigsaw puzzle method is effective by improving the all the student's academic scores. However, the II year student's performance was better than the III years.

Conclusion: Henceforth, it can be concluded that Jigsaw puzzle is effective for improving the knowledge level of the nursing students.
\end{abstract}

Keywords — Jig saw Puzzle; Cooperative Teaching and Learning; Effectiveness; Quiz; General Nursing Diploma Students; Academic Level of performance

\section{Introduction}

Learning process has to generate interest in the students and motivate them to set goals with the optimistic approach. Learning should become enjoyable experience rather than strenuous regress task. By all means education becomes an integral part of the growth process and molds each student's behavior and stimulates cognitive and critical thinking (Bradshaw \& Arlene, 2010).

Cooperative, Collaborative, action or investigative learning are some of the terms that are used, as partially synonyms in the literature, in order to define "the instructional use of small groups or teams, where peer interaction plays a key role in learning. Cooperative Learning occurs when students work together in groups to achieve shared learning goals. (Saltymakov et al., 2015). Srisumra, J et al., (2014) emphasize that the learning environment in cooperative learning encourages all the students to work together on academic tasks It is all for one, one for all method that contributes to individual and the group's success for learning. The most popular method of cooperative teaching learning method is Jigsaw Puzzle. This method is extensively used by many researchers.

\section{Literature Review}

There is a wide acceptance in the international literature, that adult learning should avoid passive approaches while embracing the ones that serve student involvement. In adult learning environments, instructorstutors are there to create the right conditions and the appropriate atmosphere that attracts the participants to learning. Under such conditions that adult learner is the centre of teaching, even more he is responsible for his /her learning (Poerksen, 2005).Cooperative teaching learning method is based on adult learning principles.

Today's environment makes passive lecture method obsolete. Hence the students need to be provided information through by guiding analyzing and presenting the available information in a most organized manner. Students must also be taught how to learn the information that will be available in future along with what is available in the present. (Beers, 2005). Cooperative teaching learning method is one of the innovative teaching methods where there is active learning happens between the groups.

According to Bowles (2000), the nursing education strives to facilitate the development of student's critical thinking skills through the appropriate instructional approaches. This concept is being supported by Karen (2013), explains that the increase in nursing degree programmes and other recent changes in nursing education. Practice policy has suggested that nurses are entering the professional sphere. Much has been made of the image of today's nurses as autonomous individuals capable of generating critical, independent thought which also has been emphasized in Director General of Education and Training Mission statement (DGET, 2010). The cooperative learning makes the students more independent 
learner. A cooperative Learning environment exists if all of these five basic elements exist (Johnson \& Johnson, 2012)

- Positive Reliance on the other group members

- Significant, constructive face- to- face interaction.

- All members must individually succeed.

- Constant use of small group skills.

- Continually learning group skills aimed at improving future effectiveness.

Spencer Kagon's Cooperative learning method is based on PIES which stands for (Kagon,1984)

P-Positive Interdependence

I- Individual Accountability

E- Equal Participation

S-Structures17

In a report, that students who fully participated in group activities, exhibited collaborative behaviors, provided constructive feedback and cooperated with their group had a higher likelihood of receiving higher test scores and course grades at the end of the semester. Results from this study support the notion that cooperative learning is an active pedagogy that fosters higher academic achievement (Brady and Tsay, 2010).

The cooperative Learning is widely used in schools but it can be used with all ages and for all subjects (Serafin, C, 2016). There are very few studies in Nursing on Cooperative teaching learning methodology. Therefore here an attempt is made to understand the contribution of the Jigsaw puzzle on the II and III year nursing student's academic performance. Furthermore this method was compared between both the groups.

\section{Aim of Study}

The study aimed to introduce the new teaching technique of "Jigsaw Puzzle" on different nursing subjects and to compare this method between II and III year General Nursing Diploma Students.

\section{Objectives}

- To introduce and implement the Jigsaw Puzzle method on " Nursing care of patients with Systemic Lupus Erythematosus" for II year General Nursing Diploma students at Oman Nursing Institute, Muscat.

- To introduce and implement the Jigsaw Puzzle method on "Nursing care of children with respiratory disorders" for III year General Nursing Diploma students at Oman Nursing Institute, Muscat.

- To assess the effectiveness of Jigsaw puzzle method and compare between II and III year nursing students.

\section{Hypothesis}

The Jigsaw puzzle will improve the academic performance of the II and III year General Nursing Diploma students.

\section{Methods and Materials}

\subsection{Population and Setting}

The Oman Nursing Institute is a teaching institution which functions under Director General of Education and Training Department (DGET) of Ministry of Health. The General Nursing Diploma is a three years course. The 162 II year nursing students who were undergoing Adult Health Nursing Course and 127 III year nursing students who were undertaking Pediatric nursing course was chosen for the study.

\subsection{Study Design}

The Interrupted time series design which is categorized under Quasi Experimental Design (One group Posttest Design) was adopted in the study.

\subsection{Sampling}

The census method was adopted where all the students of $2^{\text {nd }}$ and $3^{\text {rd }}$ year studying at Oman Nursing Institute was chosen for the study.

\subsection{Intervention}

The students undertaking Pediatric Nursing Course and adult health nursing course was introduced to the Jigsaw method. Then the 10 steps Jigsaw were implemented for the students. After the class session, quiz was given with one week interval. Then the quiz marks were compared. Here the technique is more important than the subject, the main aim is that whatever is the topic, students should be able to adopt this method and achieve the expected goal.

\section{Ten Steps Jigsaw Puzzle}

The 10 steps Jigsaw Puzzle was a new approach (Aronson, 2010). Academically the III year students were divided into 4 groups having nearly 30-33 students in each class room. Similarly the II year students are categorized in to 6 groups having approximately 25-28 students in each class room. Each classroom had 25-33 students. These students were further subdivided into smaller groups where there were 5-7 students. Hence the jig saw groups were formed in each class. Boys and girls were mixed. Leader was appointed from each group. The topic was divided

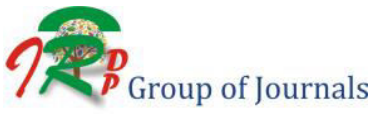


under 5 -6 segments and given to each group. Each segment was prepared by each group thoroughly and students were given read time for about 30 minutes. The students were instructed to review 2-3 times. After that all the members in each group were expert about their segment. Each one was taken out from each segment and the new group was formed in which each expert is from different segment. Now these ones will share their topic with each other. The cycle continues until the segment 5 finishes. The students have taken nearly 60 minutes to finish their session. The group got back to original jigsaw group because the expertise in all the portions/segments. Further clarification and discussion was done. 15 more minutes were given for them to wind up. The leaders have given complete written report in detail and recorded what went on in each group. The students explained to each other in their own language (Arabic) and had fun. They all enjoyed the session thoroughly.

\section{Data Analysis\& Results}

Univariate analysis: The effect of this new method was analyzed through distribution table and percentage calculation. z- Test was performed to compare the effectiveness of jigsaw between the II and III year students. The effect of teaching method was assessed by performance of students in the quiz. Table 1 shows the level of performance of II and III year students in test in the Jigsaw Puzzle.

\section{Ethical consideration}

Ethical committee approval was obtained from the Research and Ethical Review Committee of Ministry of Health in Oman. An official permission obtained from the Dean of Oman Nursing Institute.

Table 1. Comparison of quiz scores of Jigsaw Puzzle between II and III year Nursing

\begin{tabular}{|l|l|l|l|l|l|}
\hline $\begin{array}{l}\text { Gra } \\
\text { de }\end{array}$ & Percentage & II year & $\begin{array}{l}\text { Percen } \\
\text { tage }\end{array}$ & $\begin{array}{l}\text { III } \\
\text { year }\end{array}$ & $\begin{array}{l}\text { Percent } \\
\text { age }\end{array}$ \\
\hline A & $90-100$ & 1 & 0.61 & 4 & 3.14 \\
\hline A- & $85-<90$ & 0 & 0 & 4 & 3.14 \\
\hline B+ & $81-<85$ & 0 & 0 & 0 & 0 \\
\hline B & $78-<81$ & 5 & 3.08 & 8 & 6.29 \\
\hline B- & $75-<78$ & 0 & 0 & 0 & 0 \\
\hline C+ & $71-<75$ & 0 & 0 & 10 & 7.87 \\
\hline C & $68-<71$ & 26 & 16.04 & 0 & 0 \\
\hline C- & $65-<68$ & 0 & 0 & 14 & 11.02 \\
\hline D+ & $60-<65$ & 50 & 30.86 & 16 & 12.59 \\
\hline D & $50-<60$ & 67 & 41.35 & 16 & 12.59 \\
\hline F & Less than 50 & 13 & 08.02 & 55 & 43.30 \\
\hline Total & & 162 & 100 & 127 & 100 \\
\hline
\end{tabular}

\section{Students}

The table 1 reveals the Jigsaw quiz scores of II and III year nursing students and it is also expressed in the percentage. Only one student has scored grade A in II year whereas 4 students have acquired grade A in III year. When we consider the failure rate of the III years, nearly 55 students (43 percentage) of students had failed which is not a good indicator and 13 students ( 8 percent) are failed in II year which is slightly better than III year students. There is lot of fluctuations observed between other grades. In both the groups, C, C-D+, D and F grades are on the higher side. Very few are found in A and B grades. Overall the performance of the II year is better than the III year students (Fig-1). The $\mathrm{z}$ test reveals that effectiveness of the jigsaw puzzle is significant at 0.001 level hence it indicates that the level of performance of the II year is better than III year.

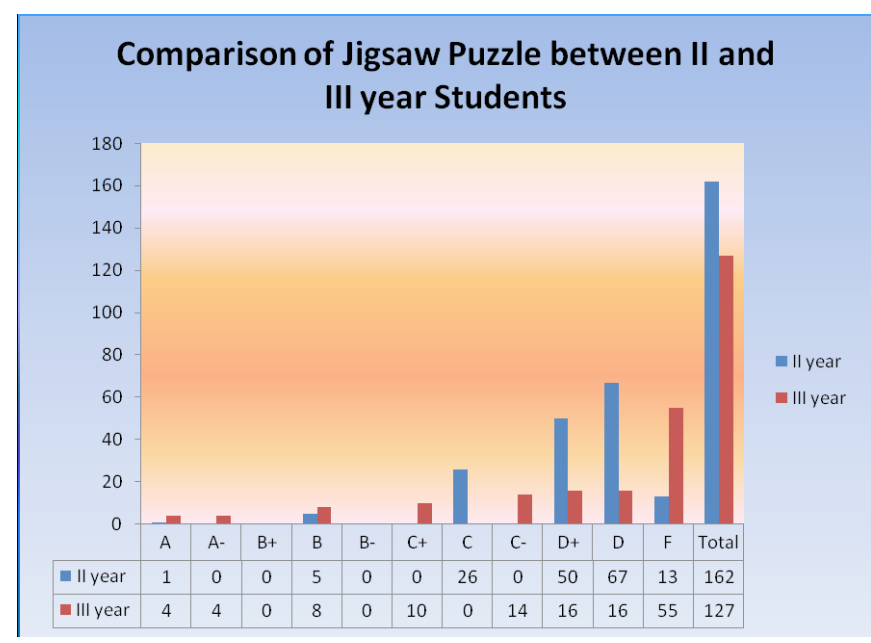

Fig.1: Comparison of Jigsaw Puzzle

\section{Discussion}

The present study shows almost nearly 40 percent of the students have scored grade D and F in II year and III year respectively. The failure rate is a crucial indicator in any educational setting. Nearly 96 percentage of the II year students have scored between 50-68 percentages. Similarly in III year nearly 80 percent of them have scored between 50-68 percentage and rest of them are scattered in all the grades. Although III year students are found more on higher grades, failure rate is more. Nearly 40 percent failure in III year is a noteworthy feature. Henceforth it can be concluded that the performance of II year is better than III year nursing students in jigsaw puzzle method however, both the groups have increased their level of performance.

None of the studies compared the cooperative methods between two groups whereas lots of studies have been done 
comparing the cooperative method with the traditional (Lecture) method.

A study conducted in University of Pittsburgh school of Nursing Pennsylvania, showed that comparing the student's midterm and final examination grades, those students taught using cooperative learning methods had an increase in both their midterm and final examinations by $10 \%$ and $15 \%$ respectively, when compared with other groups taught in the past 2 years using traditional methods. The same study has supported student responses of few positive aspects of the present study like more understanding of the subject, and felt like worked in relaxed atmosphere and so on (Slavin,2014).

There are over nine hundred research studies that corroborate the effectiveness of cooperative learning techniques over competitive and individualistic efforts. These research studies focus on a wide variety of outcomes. In fact, no other teaching methodology comes close to achieving such diverse outcomes (Johnson and Johnson, 2017). The outcomes can be classified into three distinct classifications: academic, personal and social. Cooperative Learning methods can have positive effects on student academic progress for high, average and low achievers (Slavin, 2014). In a study it was shown that this method developed critical thinking, communication and implementation skills is a result of using collaborative instructional tools such as role plays, discussions, computer simulations and projects(Karen, 2013).

All the above mentioned skills are part of nowadays so called 'key competencies', which everyone should acquire in order to achieve the goals of self-fulfillment, employability, lifelong learning and social inclusion (OECD, 2005).

\section{Limitation}

- The study was limited to Oman Nursing Institute only.

\section{Recommendations}

- The study can be done in all the nursing institutes of Oman.

- It can be compared with traditional method.

- This method can be used for the entire semester to see the better result and for more conclusive result.

\section{Conclusion}

In order to meet the needs of the growing and complex nursing environment, nursing education should strive to facilitate the development of student's critical skills. In this study, the nursing students improved their knowledge, critical thinking, communication and decision making. Only knowledge assessment was done in the study. We need to implement many innovative teaching styles and make the learning student centered. Indeed incorporation of lecture method for few sessions is also imperative.

\section{References}

[1] Aronson, E. (2010). Jigsaw classroom-Cooperative Learning. Retrieved March 19, from www.jigsaw.org/overview.htm

[2] Bradshaw, M. J. \& Arlene, J. L. (2010). Innovative Teaching strategies in Nursing \& Related Health Profession, 7th Edition, USA: Jones and Bartlett Publishers LLC.

[3] Brady. \&Tsay. (19 Feb2010). Cooperative Learning. Retrieved May 21, 2010,from wn.com/Cooperative _ learning cached

[4] Bowles, K. (2000). The relationship of critical thinking skills and the clinical judgment skills of Baccalaureate nursing students. Journal of Nursing Education, 44, 305-309.

[5] DGET, Mission Statement. Retrieved May 26,2010, from www. moh.gov.om/nv_menu.php?fNm=education/index.htm...1

[6] Johnson, D. Johnson, R. \&Stanne, (2017). Cooperative Learning: Theory, Principles, and Techniques.Retrieved: www.readingmatrix.com/conference/pp/proceedings/jacobs.pdf

[7] Johnson, D. \& Johnson, R. (2012). An Overview of Cooperative Learning. .Retrieved April 3, 2010 from http://www.clcrc.com/pages.cl.html.

[8] Kagon Spencer,. (1994). Cooperative Learning. Retrieved April 23, 2010 from hbe.com. au

[9] OECD - De. Se. Co. (2005). Definition and Selection of Key Competencies. Executive Summary (30 June 2005) Retrieved May 17, 2010, from http:// www.portal-stat.admin.ch/deseco/news.htm (August 20, 2008)

[10] Poerksen, B. (2015). Learning how to learn. Kybernetes, 34, 471484.

[11] Saltymakov, M. S., \&Frantcuzskaia, E. O. (2015). Cooperative Learning Approach to Delivering Professional Modules to Bachelor and Master Students: TPU Experience.Procedia - Social and Behavioral Sciences, 215(June), 90-97. https://doi.org/10.1016/ j.sbspro.2015.11.579

[12] Serafin, C. (2016). The Re-conceptualization of Cooperative Learning in an Inquiry- oriented Teaching, 217, 201-207. https://doi.org/10.1016/j.sbspro.2016.02.064

[13] Slavin, R. E. (2014). Cooperative Learning and Academic Achievement: Why Does Group work Work? Anales de Psicología, 30(3), 785-791. https://doi.org/10.6018/analesps.30.3.201201

[14] Srisumra, J., Nontamolee, W., \&Srijamon, S. (2014). Cooperative Learning Activities in Arts of PrathomSuksa 4 Students KhonKaen University Demonstration School Primary Section ( Modindaeng ). Procedia - Social andBehavioral Sciences, 112(Iceepsy 2013), 677682. https://doi.org/10.1016/j.sbspro.2014.01.1217. 